\title{
Diseño y validación de un cuestionario para evaluar la dimensión conceptual en educación física
}

\section{Design and validation of a questionnaire to evaluate the conceptual dimension in physical education}

\author{
Sebastián Enrique Peńa-Troncoso ${ }^{1 *}$, Sergio Toro Arévalo ${ }^{2}$, Sonia Osses Bustingorry ${ }^{3}$ y Claudio Hernández-Mosqueira ${ }^{1}$ \\ 1 Universidad de los Lagos, Puerto Montt (Chile). \\ 2 Universidad Austral de Chile (Chile). \\ 3 Universidad de la Frontera (Chile).
}

Resumen: El objetivo del estudio fue diseñar un instrumento que evalúe de forma válida y confiable la dimensión conceptual del conocimiento en educación física en estudiantes chilenos de la provincia de Llanquihue, Región de los Lagos. El estudio fue metodológicamente descriptivo. Se realizó una validación de contenido y constructo; la primera a través de un juicio de expertos; la segunda a través de un análisis factorial exploratorio con una muestra de 387 estudiantes. La fiabilidad se calculó a través de la consistencia interna y temporal del instrumento; la primera a través de la fórmula 21 de la prueba de Kuder- Richarson; la segunda mediante la aplicación de la prueba test-retest a través del Coeficiente de Correlación Intraclase (CCI), con un intervalo de una semana. Los resultados demuestran adecuados índices de validez y fiabilidad del instrumento para su uso en la población escolar chilena.

Palabras clave: contenido conceptual, validez, confiabilidad, estudiantes.
Abstract: The objective of the study was to design an instrument that validly and reliably evaluated the conceptual dimension of knowledge in physical education in Chilean students in the province of Llanquihue, Los Lagos Region. The study was methodologically descriptive. A validation of content and construct was carried out; the first through an expert judgment; the second through an exploratory factor analysis with a sample of 387 students. Reliability was calculated through the internal and temporal consistency of the instrument; The first through the formula 21 of the Kuder-Richarson test; The second by applying the test-retest test through the Intraclass Correlation Coefficient (ICC), with an interval of one week. The results show adequate indexes of validity and reliability of the instrument for its use in the Chilean school population.

Key words: conceptual contents, validity, reliability, students.

\section{Introducción}

La didáctica, como la evaluación en Educación Física (EF), debe considerar los diferentes elementos del currículo, de tal forma, que asegure que se valora tanto el grado de adquisición de las capacidades básicas, como la comprensión y denominación del lenguaje y categorías propias que dan sentido a sus objetivos. La traducción curricular de estos conocimientos son los contenidos, los cuales para asegurar su tratamiento de forma integral, deben atender a contenidos relacionados con el conocimiento en su dimensión teórico-declarativo (Arnold, 1991) denominados contenidos conceptuales; una segunda dimensión basada en procesos y en la propia ejecución, denominados contenidos procedimentales o de saber práctico (Navarro y Jiménez, 2009); y una tercera dimensión que represente la adhesión a unos valores, disposiciones y normas afines a las dos dimensiones anteriores (Blázquez, 2010), denominada contenidos actitudinales.

El conocimiento, en su dimensión conceptual es el tipo de "saber" que habitualmente se ha vinculado desde las diferentes

Dirección para correspondencia [Correspodence address]: Sebastián Enrique Peña-Troncoso. Universidad de los Lagos, Puerto Montt (Chile). E-mail: sebap988@hotmail.com asignaturas que conforman el currículo escolar, excepto en EF (Pozo, 1999). Al mismo tiempo, si revisamos las diferentes evaluaciones de los escolares en EF, existe una tendencia en la evaluación del conocimiento procedimental "saber hacer" a través de la realización de test físicos, dejando en un segundo plano el conocimiento actitudinal y conceptual. Este último, Anderson (1987) lo define como el conjunto de atributos y características que decimos de un objeto, suceso o idea. Se identifica con el "saber", siendo la información que podemos recordar exactamente como fue memorizada (McPherson, 1994; Thomas y Thomas, 1994). La característica principal de este tipo de conocimiento es que el alumno lo puede verbalizar y declarar (Ruiz, Sánchez, Durán y Jiménez, 2006) o que se conforma por medio del lenguaje (Díaz-Barriga y Hernández, 2002).

En el sector de EF los alumnos, según las bases curriculares que entrega el Ministerio de Educación de Chile (MINEDUC) (Mineduc, 2014), no solo deben ser capaces de ejecutar acciones, tareas o ejercicios, sino que, además, deben ser capaces de comprender y darle significado a cada ejecución motriz. Este aprendizaje les permitirá planificar de forma autónoma programas personales de entrenamiento físico. 
Seguidamente, diferentes estudios (Domínguez, Arroyo, Gallego, González y del Villar, 2006; Hernández, Velázquez y Martínez, 2007; Otero, González, Calvo y Molina, 2012) señalan que la evaluación en EF se ha centrado tradicionalmente en los contenidos procedimentales, dicho de otra manera, preocupados del "saber hacer". No obstante, es importante evaluar el conocimiento conceptual, principalmente porque estos saberes le dan sentido y lógica a la ejecución de cada procedimiento, además han sido, y continúan siendo, el tipo de contenidos que ha merecido mayor atención en la transmisión del "conocimiento" desde las diferentes áreas curriculares (Hernández y López, 2007).

A nuestro entender, existen varios factores que podrían explicar, en parte, el hecho de que la EF omita el desarrollo de contenidos de carácter conceptual y, por tanto, la exigencia de los correspondientes aprendizajes. Autores como Velázquez, Hernández, Martínez y Martínez de Haro, (2011) señalan dos importantes factores; uno de ellos, constituye la baja asignación horaria semanal que tiene esta asignatura; el otro, posiblemente de mayor peso, se fundamenta en la concepción hegemónica de esta disciplina, orientada a otorgarle el mayor tiempo posible de actividad motriz al estudiante durante el desarrollo de las clases.

En efecto, la acción conjunta de ambos factores ha determinado que, a lo largo de la historia de la EF, la preocupación de los profesores e investigadores se encuentren interesados en el "rendimiento deportivo" (González-Víllora, García-López, Pastor y Contreras, 2011; Méndez, 2005) y al "tiempo de aprendizaje” (Gusthart, Kelly y Rink, 1997; Metzler, 1989; Silverman, Devillier y Ramírez, 1991). Por ello, la posibilidad de que el estudiante lleve a cabo aprendizajes que incluyan el llamado sentido fuerte del "saber" (Arnold, 1991) ha sido considerada muy pocas veces en los procesos de formación integral a través de la EF.

Si bien, en EF se asume rara vez los contenidos conceptuales en la formación integral de los estudiantes, este tipo de contenidos sigue estando explícito en los programas de estudio del currículo chileno, denominados "conocimientos". Zabalza, Viciana y Lozano (2002) señalan que, los profesores de EF priorizan el aprendizaje, otorgando una clara importancia a los procedimientos sobre los conceptos, los valores y actitudes. Esta situación ratifica la concepción hegemónica de esta disciplina, permitiendo continuar orientando las clases, solo hacia la dimensión procedimental, olvidando la dimensión conceptual (Hernández et al., 2007). Según López y Moreno (2002), esta situación podría estar condicionada por una falta de preparación en su formación inicial de los profesores de EF en torno al tratamiento teórico y metodológico de hechos y conceptos.

En Chile el Sistema de Medición de la Calidad de la Educación es conocido como SIMCE y, ha sido durante las últimas décadas la herramienta que busca evaluar los co- nocimientos de las asignaturas presentes en el currículo de Chile. En el año 2001, y previa promulgación de la ley del Deporte, el MINEDUC establece un Sistema Nacional de Medición de la Calidad de la Educación Física y Deportiva para ser aplicado al finalizar la Educación Básica, llevando por nombre SIMCE de Educación Física (Mineduc, 2011). El principal objetivo del SIMCE de Educación Física es obtener un diagnóstico de la condición física de los estudiantes de $8^{\circ}$ básico (13-14 años), y a partir de sus resultados, reflexionar acerca de sus prácticas pedagógicas y elaborar planes de acción destinados a promover estilos de vida saludable en los estudiantes.

La prueba está basada en la conocida batería de test Eurofit, es decir, enfatiza la búsqueda de datos vinculados a elementos motrices y físicos. Esto ratifica una vez más, la tendencia hacia una asignatura vinculada solo a la acción deportiva, la cual atribuye al desarrollo de la competencia motriz el mayor tiempo posible de compromiso motor durante el desarrollo de las clases, omitiendo los conocimientos conceptuales (Hernández et al., 2007).

El presente estudio considera importante la práctica en EF, pero, la crítica apunta a la necesidad de valorar la dimensión conceptual, porque la experiencia de la enseñanza y aprendizaje en EF debe nacer desde la incorporación de conocimiento hacia la ejecución, ya que se considera que es así como se va construyendo una realidad que se transforma en un proceso consciente en acción y nos da cuenta de que los procesos educativos se construyen a sí mismos, desde la teoría y la práctica (Maturana y Varela, 2003; Morín, 2004; Schütz, 1974).

En virtud de nuestro objeto de estudio, el conocimiento que deben comprender los estudiantes en base a los contenidos curriculares que entrega el MINEDUC, representa múltiples descripciones e interpretaciones desde la dimensión conceptual, procedimental y actitudinal. Pozo y Gómez (1998) plantean que cada conocimiento, en el contexto de la visión más constructivista, se acerca a aquello que se vive y se reconoce como esencial dentro de la existencia de la persona en una determinada sociedad. De esta manera, no es sólo una información referente a un término, suceso, acontecimiento o mecanismo, sino que se considera conocimiento toda acción que se realiza en la vida cotidiana desde una múltiple dimensionalidad (Toro, 2007). De ahí que cualquier esfuerzo desde la didáctica específica de cada disciplina implica irrenunciablemente las tres dimensiones, de lo contrario el conocimiento siempre será parcial, provocando un aprendizaje fragmentado más que significativo (Coll, Pozo y Sarabia, 1998).

Ante la problemática de continuar formando estudiantes solo desde la dimensión procedimental y la omisión de la dimensión conceptual en las clases de EF, surge la necesidad de ampliar la mirada de la asignatura de EF como un todo, que está formada por partes, y que cada una de sus partes forma un todo; si olvidamos o favorecemos una parte, por sobre el 
todo, generamos descompensación de conocimientos; en el caso de lo conceptual privamos a los estudiantes del elemento que favorece la capacidad de comprender y asumir una cultura deportiva. Desde esta perspectiva y, ante la falta de instrumentos confiables para evaluar la dimensión conceptual del conocimiento en EF, el objetivo del estudio es, diseñar un instrumento válido y confiable que permita evaluar el conocimiento conceptual sobre educación física en estudiantes chilenos de enseñanza media de las diferentes dependencias administrativas de la Provincia de Llanquihue, Región de los Lagos.

\section{Material y métodos}

\subsection{Tipo de Estudio}

El enfoque del estudio ha sido cuantitativo de corte descriptivo-transversal, en donde se elabora y valida un cuestionario, con una muestra de escolares pertenecientes a establecimientos educacionales de la Provincia de Llanquihue, Región de los Lagos, Chile.

\subsection{Participantes}

Para asegurar una muestra representativa del estudio, se calculó en base al número de ítems del instrumento, multiplicado por diez estudiantes por ítems del cuestionario, quedando constituida por 387 escolares chilenos de enseńanza media entre 15 y 18 ańos de edad (16.0 \pm 0.8$)$. Del total de los participantes, el $57.4 \%$ (hombres) y $42.6 \%$ (mujeres). En la misma se incluyeron participantes de todas las dependencias administrativas de nuestro país municipal (32.5\%), subvencionado (33.3\%) y privado (34.1\%).

La selección de los centros educativos participantes se realizó de forma intencionada, para que nos permita obtener información en todas las dependencias. Una vez confirmados todos los colegios, se informó a los padres de la metodología y el propósito del estudio mediante carta formal remitida por los investigadores, junto con un consentimiento informado. Para participar en el estudio los estudiantes tenían que entregar el consentimiento firmado por sus padres, madres o tutores y asistir al centro el día de la prueba. Con ello se respetaron los criterios éticos, de acuerdo a la declaración de Helsinki para el estudio con seres humanos.

\subsection{Instrumento}

La versión inicial del Cuestionario sobre Aprendizajes Declarativos Conceptuales en Educación Física (CADCEF), estuvo compuesto por 60 ítems y tras el análisis del juicio de expertos, se redujo a 36 ítems. Una vez realizados los Análisis Factoriales Exploratorios (AFE), la versión final del cuestionario quedo constituido por 32 ítems. En el aspecto formal, cabe señalar que las preguntas del instrumento se plantean en forma de afirmaciones, siguiendo la estructura utilizada por Hernández et al. (2007), de manera que cada estudiante logre precisar en cada afirmación si es correcta o falsa. Con el objeto de reducir el efecto de las posibilidades de acierto por elección al azar de cada respuesta, se apeló a la sinceridad de los sujetos encuestados introduciendo cuatro opciones de respuesta para cada afirmación: "No lo sé"; "Correcto"; "Tengo dudas"; "Incorrecto". Para el segundo apartado, en donde se plantean imágenes en función de la salud postural, también se ofrecieron las mismas cuatro opciones de respuestas.

\subsection{Procedimiento}

El proceso de diseño, validación y fiabilidad del cuestionario se llevó a cabo en las siguientes cuatro etapas: elaboración del instrumento; validez de contenido; validez de constructo; consistencia interna y temporal. Para clarificar el proceso de diseño, validación y pruebas de fiabilidad, en la figura 1 se estructura un mapa conceptual.

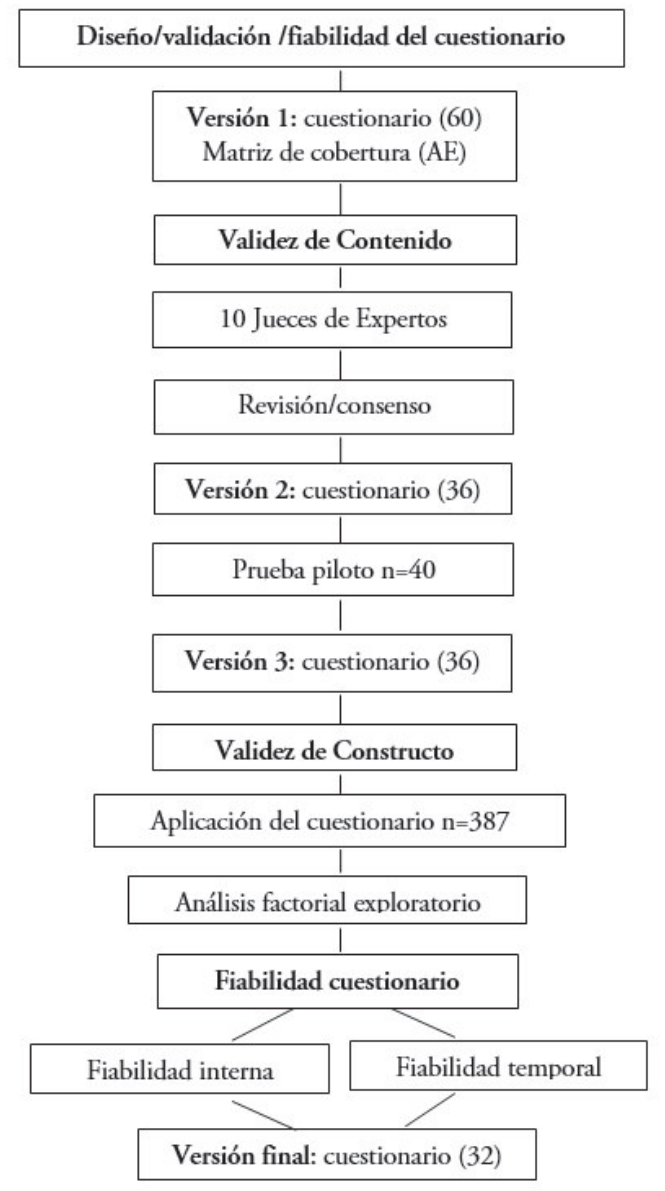

Figura 1. Diseño, validación y fiabilidad del cuestionario sobre aprendizajes conceptuales en educación física. 
I etapa: Tras la conceptualización previa del "conocimiento conceptual” y análisis de los programas de estudio de EF que entrega el MINEDUC, se decide elaborar una matriz de cobertura, para lograr cubrir todos los Aprendizajes Esperados (AE) que tienen directa relación con los aprendizajes conceptuales. Posteriormente, se construye el cuestionario considerando como requisitos de partida los que indica (Ramos, Giménez, Muñoz y Lapaz, 2006); brevedad, sencillez, vocabulario comprensible y adaptado tanto a la edad como a las características sociales y culturales de los estudiantes, preguntas breves, motivador y atractivo en su diseńo.

El instrumento consideró todas las temáticas que actualmente forman parte del programa de estudio de EF: vida activa saludable; condición física y principios de entrenamiento; deportes; actividades motrices físicas alternativas en el entorno natural; habilidades expresivo-motrices y salud postural.

II etapa: Para alcanzar niveles óptimos de validez de contenido, se utilizó la técnica de jueces expertos, la cual se define como el grado en que una prueba mide de forma adecuada lo que pretende medir (Thomas y Nelson, 2007; Wiersma, 2001). Las variables que se utilizaron para valorar la validez de contenido del instrumento fueron; grado de adecuación de las preguntas del cuestionario (a nivel conceptual); grado de pertenencia al objeto de estudio; y grado de adecuación a nivel de definición y comprensión. Los jueces expertos indicaron la necesidad de que la pregunta forme, o no, parte del cuestionario y el grado de pertenencia de las preguntas en el instrumento (escala de uno al 10). Siguiendo la propuesta de Bulger y Housner (2007) se eliminarán todas aquellas preguntas con valores inferiores a siete, se modificarán los valores entre 7.1 y 8 , y se aceptarán los superiores a 8.1. Para comprobar cuáles son las dificultades en relación a la redacción, adecuación y terminología específica de las diferentes preguntas y respuestas, se realizó una prueba piloto con 40 estudiantes de similares características a los que participaron del estudio.

III etapa: Para explorar la estructura factorial de los ítems que componen el instrumento, se decide recodificar las 36 variables (preguntas) a dicotómicas, principalmente, porque cada una de estas, estaba compuesta sólo por una respuesta correcta. Posteriormente, se realiza el AFE, para asegurar la calidad de los datos y tipos de variables, detección de valores outliers, así como el cálculo de las distintas variables necesarias de los diferentes constructos planteados en el cuestionario. Se realiza el Análisis Factorial Exploratorio del instrumento en dos etapas, principalmente porque el segundo apartado del instrumento estaba compuesto por imágenes que contenían respuestas múltiples, y esto, no permitía clarificar la agrupación de las variables en los diferentes factores. El primer AFE se realiza con los ítems que estaban compuestos por afirmaciones (tabla 2) y el segundo AFE se realiza con los ítems que estaban planteados a través de imágenes (tabla
3). Solo en el primer Análisis Factorial Exploratorio (afirmaciones) se excluyeron cuatro ítems (3, 4, 9 y 19) los cuales arrojaron un índice de dificultad difícil bajo un .3 (Ayala, 2013). Ambos AFE se realizaron a través de una correlación Tetrachoric (Choi, Kim, Chen y Dannels, 2011) por ser variables dicotómicas.

IV etapa: La fiabilidad se define como la reproductibilidad de una medida (Thomas y Nelson, 2007). Para determinar la consistencia interna del cuestionario, se utiliza la fórmula 21 de la prueba de Kuder- Richarson diseñada para variables dicotómicas (Silva, 2009), como es el caso del presente estudio y, para alcanzar niveles óptimos de fiabilidad temporal del instrumento, se utiliza la técnica de test re-test a través del Coeficiente de Correlación Intraclase (CCI), el cual nos permite valorar la concordancia entre ambas medidas. Siguiendo la propuesta de Baumgartner (2000), ambas mediciones estuvieron separadas en el tiempo por una semana, en circunstancias idénticas.

\subsection{Análisis estadísticos}

Los análisis preliminares de normalidad, descriptivos y de fiabilidad se efectuaron con el programa SPSS 21.0. Posteriormente, para los Análisis Factoriales Exploratorios se utiliza el programa FACTOR 10.4 (Lorenzo-Seva y Ferrando, 2016). Respecto a la extracción de factores comunes de los ítems, se analiza empleando el Robust Unweighted Least Squares (RULS) como método de extracción. Como procedimiento para explorar el número de factores se empleó la Optimal implementation of Parallel Analysis (PA) (Timmerman y Lorenzo-Seva, 2011) todo esto se realiza sobre la matriz tetrachoric. Se utiliza también una rotación Normalized Varimax.

\section{Resultados}

\subsection{Descriptivos}

La tabla 1 muestra un análisis descriptivo de los participates en el estudio en cuanto al sexo y la dependencia administrativa, demostrando una distribución similar para ambas variables.

Tabla 1. Descripción de los participantes.

\begin{tabular}{cccc}
\hline & \multicolumn{3}{c}{ Sexo de los estudiantes } \\
Dependencia administrativa & Masculino & Femenino & Total \\
\hline Municipal & 75 & 51 & 126 \\
Subvencionado & 54 & 75 & 129 \\
Particular & 93 & 39 & 132 \\
\hline Total & 222 & 165 & 387 \\
\hline
\end{tabular}




\subsection{Análisis factoriales exploratorios}

El resultado para la medida de adecuación muestral del primer Análisis Factorial Exploratorio (afirmaciones) confirmó el análisis con un (Kaiser-Meyer-Olkin) $\mathrm{KMO}=.76$, por lo tanto, la idea es aceptable, y el registro de la prueba de esfericidad de Bartlett es .00. El segundo Análisis Factorial Exploratorio (imágenes), confirmó el análisis con un (KaiserMeyer-Olkin) $\mathrm{KMO}=.68$, y el registro de la prueba de esfericidad de Bartlett es .00. Ambos análisis nos permitieron asumir que existe una correlación interna en las respuestas de la aplicación del instrumento. Los ítems (afirmaciones) se agruparon en tres categorías o factores: factor 1 (ejercicio físico y salud), factor 2 (deporte y expresión motriz), factor 3 (actividad física y motora al aire libre) (tabla 2), los cuales explican el $.46 \%$ de la varianza total. Los ítems (imágenes) se agruparon en dos factores: factor 4 (salud postural) y factor 5 (flexibilidad) (tabla3), explicando el .44\% de la varianza total.

Tabla 2. Análisis factorial exploratorio de los ítems (afirmaciones) del cuestionario.

\begin{tabular}{lccc}
\hline ITEMS & Factor 1 & Factor 2 & Factor 3 \\
\hline Ítem 1 & .326 & & \\
Ítem 2 & .435 & & \\
Ítem 5 & .326 & & \\
Ítem 6 & .351 & & \\
Ítem 7 & .469 & & \\
Ítem 8 & & .416 & \\
Ítem 10 & & .518 & \\
Ítem 11 & .317 & .509 & \\
Ítem 12 & & .528 & \\
Ítem 13 & & .673 & .374 \\
Ítem 14 & & .436 & \\
Ítem 15 & & .443 & \\
Ítem 16 & & .608 & \\
Ítem 17 & & .653 & .401 \\
Ítem 18 & & .506 & .697 \\
Ítem 20 & & & .389 \\
Ítem 22 & .658 & & \\
Ítem 23 & & & \\
Ítem 24 & & & \\
\hline
\end{tabular}

Tabla 3. Análisis factorial exploratorio de los ítems (imágenes) del cuestionario.

\begin{tabular}{lcc}
\hline ITEMS & Factor 4 & Factor 5 \\
\hline Imagen 25 & .418 & \\
Imagen 26 & .372 & \\
Imagen 27 & .439 & \\
Imagen 28 & .425 & \\
Imagen 29 & .518 & \\
Imagen 30 & .680 & \\
Imagen 31 & .694 & \\
Imagen 32 & .454 & .939 \\
Imagen 33 & & .437 \\
Imagen 34 & .347 & .538 \\
Imagen 35 & & .836 \\
Imagen 36 & & \\
\hline
\end{tabular}

\subsection{Consistencia interna y temporal}

Debido a las características de respuesta del instrumento (dicotómicas), en el análisis de la consistencia interna se utiliza la fórmula 21 de la prueba de Kuder- Richarson, obteniendo un coeficiente de .78, valor que nos permite estimar una consistencia interna fuerte del instrumento (Hair, Black, Babin y Anderson, 2009).

Para establecer la consistencia temporal del instrumento, se realiza un análisis del Coeficiente Correlación Intraclase, entre el test y re-test, en el cual se obtuvo un coeficiente de .75 , evidenciando que existe una relación altamente significativa $(p<.01)$ (tabla 4$)$. Si bien el valor del CCI que define una fiabilidad satisfactoria del instrumento es arbitrario y depende del uso que de ella se haga, en general, se ha indicado que valores del CCI por debajo del 4 representan baja fiabilidad, que valores entre .4 y .75 representan una fiabilidad entre regular y buena, y que valores por encima de .75 representan una fiabilidad excelente (Prieto, Lamarca y Casado, 1998).

Tabla 4. Correlación intraclase entre el test y re-test.

\begin{tabular}{lcccc} 
& & \multicolumn{3}{c}{$95 \%$ de intervalo de confianza } \\
& Correlación intraclase & Límite inferior & Límite superior & Sig \\
\hline Medidas únicas & .602 & .270 & .806 & .001 \\
Medidas promedio & .751 & .425 & .892 & .001 \\
\hline
\end{tabular}




\section{Discusión}

El cuestionario obtenido tiene por objeto la valoración de la dimensión del conocimiento conceptual en EF. La revisión realizada en trabajos que diseñan y/o validan instrumentos similares (Espejel, Meza, Ruiz, Trejo y López, 2016; Figueiredo, Lago y Fernández, 2008; García, 2001; García-Santos e Ibáńez, 2016; Gil-Madrona, Pita-Lozano, Díaz-Suárez y López-Sánchez, 2017; Iglesias, 2006; Moreno, Moreno, García-González, Gil y Del Villar, 2010; Otero et al., 2012) muestran la importancia de establecer buenos índices de ajuste para hacer válido y fiable su utilización.

No obstante, el aporte del presente estudio es su realización en un ámbito escolar que tiene escasas investigaciones, dado que la mayoría de las investigaciones en EF se enmarcan en torno al "rendimiento deportivo" (González-Víllora et al., 2011; Lund y Kirk, 2010) y al "tiempo de aprendizaje" (Gusthart, Kelly y Rink, 1997; Metzler, 1989; Silverman et al., 1991). Estos estudios, han hecho que el concepto de eficacia docente este asociado al rendimiento que obtienen los estudiantes, valorado a través de pruebas motrices como el SIMCE y diferentes test físicos.

Los datos obtenidos en el presente estudio indican que, a pesar de que los jueces expertos indiquen que los ítems son correctos, y que su grado de comprensión y redacción es alto, puede ocurrir que los participantes que deben contestar el instrumento no perciban el mismo criterio (Bulger y Housner, 2007) o viceversa, ítems que tienen baja valoración de comprensión por los jueces expertos, los participantes obtienen un alto grado de comprensión.

Con respecto a la validez de constructo, diferentes autores (Messick, 1980; Pérez, Chacón y Moreno, 2000) señalan la importancia de estos análisis, los cuales permiten integrar consideraciones de la validez de contenido en un marco común para probar hipótesis acerca de relaciones teóricamente relevantes. Desde esta línea, fue importante realizar el AFE, ya que nos permitió, por un lado; clarificar las dimensiones o factores del instrumento, en los cuales se asociaban los ítems y, por otro; determinar los índices de dificultad de cada uno de ellos.

En función de la fiabilidad interna del cuestionario, se obtiene un coeficiente de .78 , valor que nos permite estimar una consistencia interna recomendada, en este caso para un instrumento de estas características (Henson, 2001). La consistencia interna como enfoque para hallar la fiabilidad de un instrumento es la perspectiva utilizada por (Cuéllar, Delgado y Delgado, 2004; McGee y Farrow, 1987) en instrumentos de similares características.

La fiabilidad temporal como procedimiento para mejorar las cualidades psicométricas del instrumento parece pertinente a la luz de otros trabajos similares. Moreno et al. (2010) acreditaron la fiabilidad de un instrumento de conocimiento declarativo en voleibol, aplicando al mismo tiempo el enfoque de consistencia interna de este trabajo y la fiabilidad temporal, obteniendo .77 y .76 respectivamente. Por ello, parece adecuado el .75 obtenido en la presente investigación. Estas pruebas de fiabilidad interna y temporal son señaladas necesarias por varios autores (Baumgartner, 2000; CarreteroDios y Pérez, 2007; Silverman y Subramanian, 2000).

Una validez de contenido y constructo, más una fiabilidad basada en la consistencia interna y temporal son las propiedades psicométricas del cuestionario final. Desde la validez de contenido, se aprecian interesantes aportes por parte de los jueces expertos. Estos aportes están principalmente vinculados a la mejora de la comprensión de los ítems, aunque en algunos casos se hacía alusión a la necesidad de eliminar ítems e incluso incorporar otros. Al analizar la validez con respecto al grado de comprensión de los sujetos, cabe destacar la enorme necesidad de realizar pruebas pilotos, más allá de las apreciaciones que puedan determinar los jueces expertos.

\section{Conclusiones}

A partir de los resultados obtenidos, se puede establecer que el diseño del CADCEF dispone de niveles óptimos de validez y confiabilidad para evaluar la dimensión del conocimiento conceptual en EF en escolares chilenos de las diferentes dependencias administrativas de la provincia de Llanquihue, Región de los Lagos. Desde esta mirada, el cuestionario puede ser considerado como una herramienta útil para valorar uno de los contenidos más importantes en la generación de conocimiento en el área de EF. Así, mismo, representa una alternativa o complemento de evaluación directa del SIMCE de EF en Chile, el cual hace siete años ha sido la herramienta de medición estandarizada de la disciplina, pero solo, considerando la condición física de los estudiantes, dicho de otra manera, sólo preocupados de la dimensión procedimental.

Podría resultar interesante el SIMCE en EF, si su objetivo fuera conocer el estado actual de los escolares chilenos, desde una múltiple dimensionalidad (conceptual, procedimental y actitudinal). De lo contrario, estaríamos propiciando que la clase de EF, perdiera su carácter educativo, centrándose principalmente en la obtención de resultados, perdiendo así, el carácter epistémico de la disciplina.

Más aún, realizar esta medición a nivel nacional, conlleva un gasto excesivo en tiempo y dinero, tanto en la medición en si, como en la preparación de los evaluadores. Con el CADCEF se podría simplificar el proceso, o bien, puede ser un complemento en la evaluación de los estudiantes, logrando obtener una evaluación mucho más integral de la EF en Chile. También, el instrumento puede entregar al contexto educativo y, específicamente a los docentes de EF, una herramienta diagnóstica que facilite el proceso de enseńanza y aprendizaje, logrando ampliar la mirada de la asignatura de 
EF vinculada a la importancia del conocimiento conceptual en el proceso de formación de los estudiantes.

\section{Limitaciones}

Una de las principales limitaciones del estudio, fue no analizar la validez concurrente, por lo que se sugiere complementar la validez externa del instrumento analizando la asociación de los factores del CADCEF con otros constructos teóricamente similares. Además, se necesita continuar el proceso de evaluación psicométrica del instrumento, para que pueda ser utilizado en diversas edades y las diferentes regiones del país.

\section{Bibliografía}

1. Anderson, J. (1987). Skill acquisition: Compilation of weak-method problem solutions. Psychological Review, 94, 192-210.

2. Arnold, P. (1991). Educación física, movimiento y currículum. Madrid: Morata.

3. Ayala, A. (2013). Índice de dificultad y asimetría de los ítems en las pruebas pedagógicas. Horizonte de la Ciencia, 3(5), 65-74. doi: 10.26490/ uncp.horizonteciencia.2013.5.77

4. Baumgartner, T. (2000). Estimating the stability reliability of a store. Measurement in Physical Education and Exercise Science, 4(3), 175-178. doi: $10.1207 / S 15327841 \mathrm{Mpee} 0403 \_3$

5. Blázquez, D. (2010). La educación física. Barcelona. Inde.

6. Bulger, S., \& Housner, L. (2007). Modified Delphi investigation of exercise science in physical education teacher education. Journal of Teaching in Physical Education, 26(1), 57-80. doi: 10.1123/jtpe.26.1.57

7. Carretero-Dios, H., \& Pérez, C. (2007). Normas para el desarrollo y revisión de estudios instrumentales: consideraciones sobre la selección de test en la investigación psicológica. International Journal of Clinical and Health Psychology, 7(3), 863-882.

8. Choi, J., Kim, S., Chen, J., \& Dannels, S. (2011). A comparison of maximum likelihood and Bayesian estimation for polychoric correlation using Monte Carlo simulation. Journal of Educational and Behavioral Statistics, 36, 523-549. doi: 10.3102/1076998610381398

9. Coll. C., Pozo, J., \& Sarabia, B. (1998). Los contenidos en la reforma. Madrid. Santillana.

10. Cuéllar, M., Delgado, M., \& Delgado, M. (2004). Construcción y validación de un instrumento para la evaluación de aspectos conceptuales en danza. Tándem: Didáctica de la Educación Física, 4(14), 93-105. doi: 10.4067/S0718-07052017000100009

11. Díaz-Barriga, F., \& Hernández, G. (2002). Estrategias docentes para un aprendizaje significativo. Una interpretación constructivista. México: Mc Graw Hill.

12. Domínguez, A., Arroyo, M., Gallego, D., González, L., \& del Villar, F. (2006). Estudio del conocimiento declarativo en función de la experiencia y de la edad en jugadores jóvenes de voleibol. Cultura, Ciencia y Deporte, 2(5), 73-80. doi: 10.12800/ccd.v2i5.175

13. Espejel, H., Meza, E., Ruiz, Z., Trejo, M., \& López, C. (2016). Propiedades psicométricas de la Escala de Motivación en el Deporte revisada (SMS-II) adaptada al espańol hablado en México. RICYDE. Revista Internacional de Ciencias del Deporte, 12(44), 107-120. doi: 10.5232/ ricyde2016.04402

14. Figueiredo, L., Lago, C., \& Fernández, M. (2008). Análisis del efecto de un modelo de evaluación recíproca sobre el aprendizaje de los deportes de equipo en el contexto escolar. Motricidad: Revista de Ciencias de la Actividad Física y del Deporte, 21, 99-117.

15. García, J. (2001). Adquisición de la competencia para el deporte en la infancia: el papel del conocimiento y la toma de decisiones en balonmano. Tesis Doctoral. Universidad de Extremadura.

16. García-Santos, D., \& Ibáńez, S. (2016). Diseńo y validación de un instrumento de observación para la valoración de un árbitro de baloncesto (IOVAB). SPORT TK-Revista EuroAmericana de Ciencias del Deporte, 5(2), 15-26.

17. Gil-Madrona, P., Pita-Lozano, A., Díaz-Suárez, A., \& López-Sánchez, G. (2017). Validación del cuestionario: "Perception of competence in middle school PE” al contexto espańol. RICYDE. Revista Internacional de Ciencias del Deporte, 13(48), 172-187. doi: 10.5232/ricyde2017.04807

18. González-Víllora, S., García-López, L. M., Pastor, J. C., \& Contreras, O. (2011). Conocimiento táctico y la toma de decisiones en jóvenes jugadores de fútbol (10 ańos). Revista de Psicología del Deporte, 20(1), 79-97.

19. Gusthart, J., Kelly, I., \& Rink, J. (1997). The validity of the Qualitative Measures of Teaching Performance Scale as a Measure on Teacher Effectiveness. Journal of Teaching in Physical Education, 16, 196-210. doi: 10.1123/jtpe.16.2.196

20. Hair, J., Black, W., Babin, B., \& Anderson, R. (2009). Multivariate Data Analysis. New York: Pearson Prentice Hall.

21. Henson, R. (2001). Understanding internal consistency reliability estimates: A conceptual primer on coefficient alpha. Measurement and Evaluation in Counseling and Development, 34(3), 177-189.

22. Hernández, J., \& López, A. (2007). Qué saben los escolares españoles. Conceptos claves en Educación Física y su evaluación. En Hernández \& Velázquez (Coord.). La Educación Física, los estilos de vida y los adolescentes: cómo son, cómo se ven, qué saben y qué opinan, (pp.169-204). Barcelona: Graó.

23. Hernández, J., Velázquez, R., \& Martínez, M. (2007). Reformas Curriculares y Educación Física: los Conocimientos Teórico-Conceptuales de la Población Escolar Española. Archivos Analíticos de Políticas Educativas, 15(15). doi: 10-4438/1988-592X-RE-2010-356-055

24. Iglesias, D. (2006). Efecto de un protocolo de supervisión reflexiva sobre el conocimiento procedimental, la toma de decisiones y la ejecución en jugadores jóvenes de baloncesto (Tesis Doctoral). Universidad de Extremadura, Cáceres.

25. López, A., \& Moreno, J. (2002). Aprendizaje de hechos y conceptos en educación física. Una propuesta metodológica. Apunts: Educación Física y Deportes, 69, 19-26.

26. Lorenzo-Seva, U., \& Ferrando, P. (2016). FACTOR: A computer program to fit the exploratory factor analysis model. Behavior research methods, 38(1), 88-91. doi: 10.3758/BF03192753

27. Lund, J., \& Kirk, M. (2010). Performance-based assessment for middle and high school physical education. Champaign: Human Kinetics.

28. Maturana, H., \& Varela, F. (2003). El árbol del conocimiento: las bases biológicas del entendimiento humano. Buenos Aires, Argentina: Grupo Editorial Lumen.

29. McGee, R., \& Farrow, A. (1987). Test questions for physical education activities. Champaign: Human Kinetics.

30. McPherson, S. (1994). The development of sport expertise: Mapping the tactical domain. Quest, 46(2), 223-240. doi: 10.1080/00336297.1994.10484123

31. Méndez, A. (2005). Hacia una evaluación de los aprendizajes consecuente con los modelos alternativos de iniciación deportiva. Tándem: Didáctica de la Educación Física, 17, 38-58.

32. Messick, S. (1980). Test validity and ethics of assessment. American Psychologist, 35, 1012-1027. doi: 10.1002/j.2333-8504.1979.tb01178.x 
33. Metzler, M. (1989). A review of research on time in sport pedagogy. Journal of Teaching in Physical Education, 8(2), 87-103. doi: 10.1123/ jtpe.8.2.87

34. Ministerio de Educación (2011). Informe de resultados Educación Física. SIMCE octavo básico 2011. Santiago de Chile: autor.

35. Ministerio de Educación. (2014). Bases curriculares 2013, $7^{\circ}$ básico a $2^{\circ}$ medio. Santiago de Chile: autor.

36. Moreno, A., Moreno, P., García-González, Gil, A., \& Del Villar, F. (2010). Desarrollo y validación de un cuestionario para la evaluación del conocimiento declarativo en voleibol. Motricidad: Revista de Ciencias de la Actividad Física y del Deporte, 25, 183-195.

37. Morín, E. (2001). El método I. La naturaleza de la naturaleza. Madrid, España. Cátedra.

38. Navarro, V., \& Jiménez, F. (2009). El conocimiento práctico de la educación física desde una visión epistemológica actual. Acción Motriz, 3 25-32.

39. Otero, F., González, J., Calvo, A., \& Molina, E. (2012). Contenidos conceptuales en Educación Física: efecto de un programa de intervención en el primer ciclo de primaria. EmásF: Revista Digital de Educación Física, 3(16), 55-68. Recuperado de http://emasf.webcindario. com/

40. Pérez, J., Chacón, S., \& Moreno, R. (2000). Validez de constructo: el uso de análisis factorial exploratorio-confirmatorio para obtener evidencias de validez. Psicothema, 12(2), 442-446.

41. Pozo, J. (1999). Aprendizaje de contenidos y desarrollo de capacidades en la educación secundaria. En Coll (Coord.). Psicología de la Instrucción: la enseńanza y el aprendizaje en la Educación Secundaria. Barcelona. Horsori.

42. Pozo, J., \& Gómez, M. (1998). Aprender y enseñar ciencias. Barcelona. Morata.

43. Prieto, L., Lamarca, R., \& Casado, A. (1998). La evaluación de la fiabilidad en las observaciones clínicas: el coeficiente de correlación intraclase. Medicina Clínica, 110(4), 142-145.

44. Ramos, R., Giménez, A., Muñoz, E., \& Lapaz, M. (2006). Cuestionario de evaluación de la autoestima para educación primaria (A-EP). Madrid. TEA Ediciones.

45. Ruiz, L., Sánchez, M., Durán, J., \& Jiménez, C. (2006). Los expertos en el deporte: su estudio y análisis desde una perspectiva psicológica. Anales de Psicología, 1(22), 134- 142.

46. Schütz, A. (1974). El problema de la realidad social. Buenos Aires, Argentina. Ediciones Paidós.

47. Silva, F. (2009). Validez y confiabilidad de los instrumentos de recolección de datos. Recuperado de https://es.slideshare.net/rosilfer/validezconfiabilidad

48. Silverman, S., Devillier, R. \& Ramirez, T. (1991). The validity of academic learning time-physical education (ALT-PE) as a process measure of achievement. Research Quarterly for Exercise and Sport, 62(3), 319-325. doi: 10.1080/02701367.1991.10608729

49. Silverman, S., \& Subramaniam, P. (2000). Student attitude toward physical education and physical activity: A review of measurement issues and outcomes. Journal of Teaching in Physical Education, 19(1), 97125. doi: $10.1123 /$ jtpe.19.1.97

50. Timmerman, M., \& Lorenzo-Seva, U. (2011). Dimensionality Assessment of Ordered Polytomous Items with Parallel Analysis. Psycholo gical Methods, 16(2), 209-220. doi: 10.1037/a0023353

51. Thomas, J., \& Nelson, J. (2007). Métodos de investigación en actividad física. Barcelona: Paidotribo.

52. Thomas, K., \& Thomas, J. (1994). Developing expertise in sport: The relation of knowledge and performance. International Journal of Sport Psychology, 25, 295-315.

53. Toro, S. (2007). Una aproximación epistemológica a la didáctica de la motricidad desde el discurso y práctica docente. Estudios Pedagógicos, 33(1), 29-43. doi: 10.4067/S0718-07052007000100002

54. Velázquez, R., Hernández, J., Martínez, M., \& Martínez de Haro, V. (2011). Educación Física y conocimiento teórico-conceptual: estudio trans-cultural en Argentina, Brasil y España. Revista de Educación, 356 653-675.

55. Wiersma, L. (2001). Conceptualization and development of the sources of enjoyment in youth sport questionnaire. Measurement in Physical Education and Exercise Science, 5(3), 153-177. doi: 10.1207/ S15327841MPEE0503_3

56. Zabala, M., Viciana, J., \& Lozano, L. (2002). La planificación de los deportes en la educación física de ESO. Revista Digital EF deportes, 8(48). Recuperado de http://www.efdeportes.com/efd48/eso.htm 


\section{Cuestionario sobre aprendizajes declarativos conceptuales en educación física}

Queremos conocer lo que sabes sobre la dimensión conceptual del conocimiento de educación física. Por favor, recuerda que el cuestionario es anónimo. Contesta con sinceridad. Marca el número:
1: Si no lo sabes

2: Si crees que es correcto

3: Si crees saberlo pero tienes dudas

4: Si crees que es incorrecto.

Género: M $\square_{(1)}$ F $\square_{(2)}$ (Marca con una X)

Edad: $15 \underset{(1)}{\square} 16 \underset{(2)}{\square} 17 \quad \underset{(3)}{\square} 18 \quad \square_{(4)}^{\square} 19 \quad \underset{(5)}{\square}$

Dependencia: Municipal $\square$ Subvencionado $\square$ Particular $\square$

Perteneces a alguna Etnia: Si $\square_{(1)}$ No $\square_{(2)}$ Cual:

Tienes alguna discapacidad: Si $\underset{(1)}{\square}$ No $\underset{(2)}{\square}$ Cual:

\begin{tabular}{|c|c|c|c|c|}
\hline & $\begin{array}{l}\text { No } \\
\text { lo sé }\end{array}$ & $\begin{array}{l}\text { La afirmación } \\
\text { es correcta }\end{array}$ & $\begin{array}{l}\text { Tengo } \\
\text { dudas }\end{array}$ & $\begin{array}{l}\text { La afirmación } \\
\text { es incorrecta }\end{array}$ \\
\hline 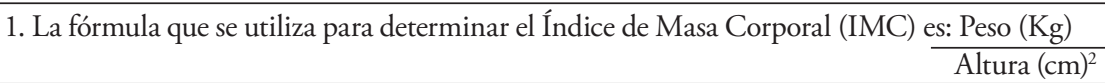 & 1 & 2 & 3 & 4 \\
\hline $\begin{array}{l}\text { 2. El ejercicio de tocar las puntas de los pies con las piernas completamente extendidas } \\
\text { permite mejorar la flexibilidad. }\end{array}$ & 1 & 2 & 3 & 4 \\
\hline $\begin{array}{l}\text { 3. Los ejercicios cardiovasculares se caracterizan por ser de larga duración y baja intensi- } \\
\text { dad. }\end{array}$ & 1 & 2 & 3 & 4 \\
\hline 4. El diafragma es el músculo principal responsable de la respiración abdominal. & 1 & 2 & 3 & 4 \\
\hline $\begin{array}{l}\text { 5. El calentamiento previo a la actividad física sirve para activar el sistema cardiorespi- } \\
\text { ratorio. }\end{array}$ & 1 & 2 & 3 & 4 \\
\hline $\begin{array}{l}\text { 6. La condición física depende de los genes, la edad, el sexo, el entrenamiento y los } \\
\text { hábitos de salud. }\end{array}$ & 1 & 2 & 3 & 4 \\
\hline $\begin{array}{l}\text { 7. Cuando hablamos de la perdida de agua corporal, nos estamos refiriendo a la deshidra- } \\
\text { tación. }\end{array}$ & 1 & 2 & 3 & 4 \\
\hline $\begin{array}{l}\text { 8. La posesión del balón en cada jugada por cada equipo en el basquetbol, es de } 25 \\
\text { segundos. }\end{array}$ & 1 & 2 & 3 & 4 \\
\hline $\begin{array}{l}\text { 9. Cuando hablamos del conjunto de acciones colectivas que forman el sistema de juego } \\
\text { de un equipo para lograr su objetivo, nos estamos refiriendo a la táctica. }\end{array}$ & 1 & 2 & 3 & 4 \\
\hline $\begin{array}{l}\text { 10. Cuando hablamos de lanzar el balón sin entrar en el área de seis metros, estamos } \\
\text { refiriéndonos a una zona restringida del Balonmano. }\end{array}$ & 1 & 2 & 3 & 4 \\
\hline 11. El tiempo de juego de un partido de basquetbol es de 4 cuartos de 20 minutos. & 1 & 2 & 3 & 4 \\
\hline $\begin{array}{l}\text { 12. Siempre que te desplazas sin el balón por el terreno de juego para intentar conseguir } \\
\text { un pase o un gol, estas en acción de desmarque. }\end{array}$ & 1 & 2 & 3 & 4 \\
\hline 13. El costillar es uno de los bailes tradicionales de la zona norte. & 1 & 2 & 3 & 4 \\
\hline 14. La expresión corporal se puede desarrollar a través de la danza. & 1 & 2 & 3 & 4 \\
\hline 15. La pista de atletismo reglamentaria tiene 300 metros de distancia. & 1 & 2 & 3 & 4 \\
\hline 16. El ritmo es todo aquello que es repetido con regularidad (combinación de duraciones). & 1 & 2 & 3 & 4 \\
\hline $\begin{array}{l}\text { 17. La recomendación esencial para armar un campamento es optar por los sitios que no } \\
\text { hayan sido utilizados frecuentemente. }\end{array}$ & 1 & 2 & 3 & 4 \\
\hline
\end{tabular}




\begin{tabular}{lllll}
\hline 18. Los desechos de un campamento deben ser guardados, para posteriormente eliminarlos. & 1 & 2 & 3 & 4 \\
\hline 19. La alimentación para un recorrido de senderismo debe ser baja en calorias. & 1 & 2 & 3 & 4 \\
\hline $\begin{array}{l}\text { 20. Lo importante de la montańa es disfrutarla en el momento que cada uno desee, ya } \\
\text { sea solo o en compañía, eligiendo sobre la marcha donde se quiere ir y que se quiere ver. }\end{array}$ & 1 & 2 & 3 & 4 \\
\hline
\end{tabular}

1= No lo sé 2= Correcto 3= Tengo dudas 4= Incorrecto

¿Cuál de los ejercicios crees que está bien ejecutado?

(21)

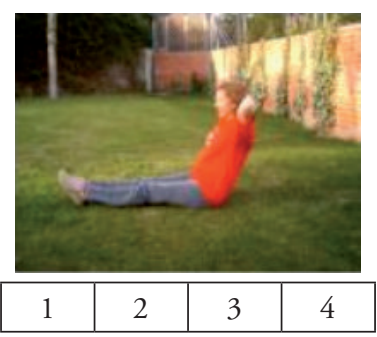

(25)

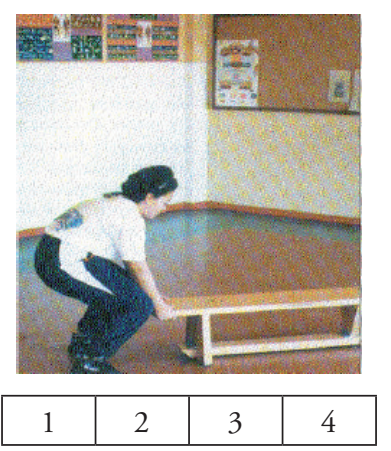

(22)

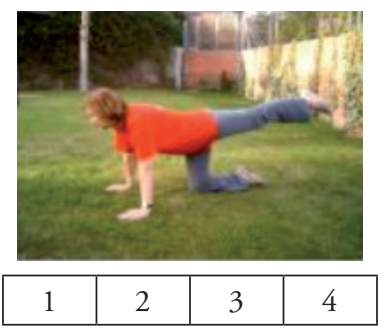

(26)
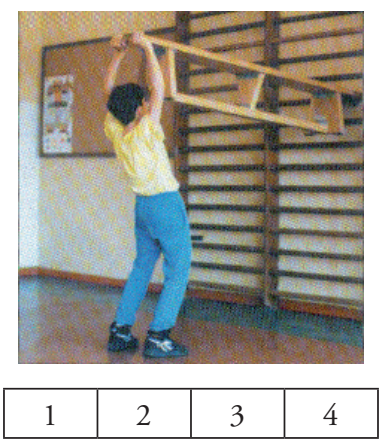

(23)

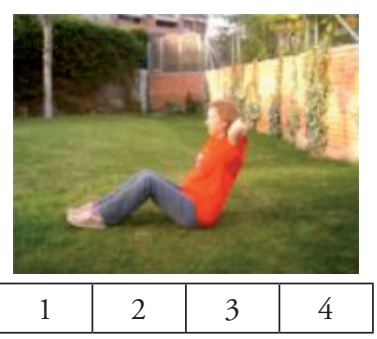

(27)
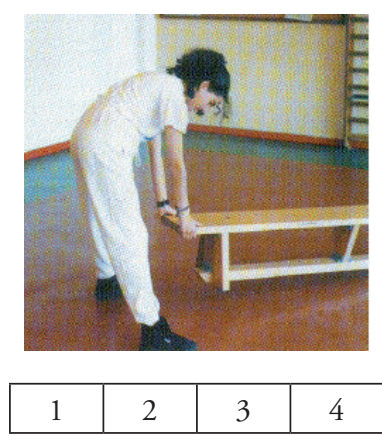

(24)

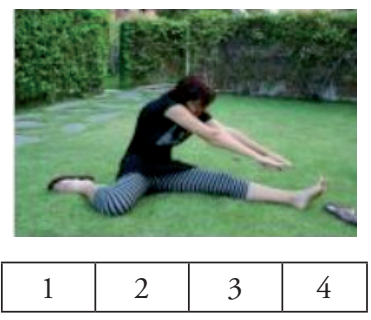

(28)

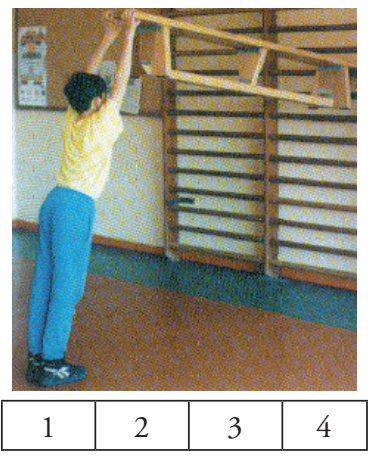

¿Cuál de los ejercicios crees que permite el estiramiento de los cuádriceps?

(29)

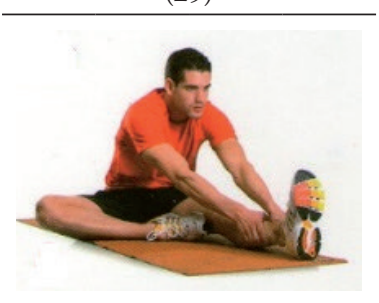

\begin{tabular}{|l|l|l|l|}
\hline 1 & 2 & 3 & 4 \\
\hline
\end{tabular}
(30)

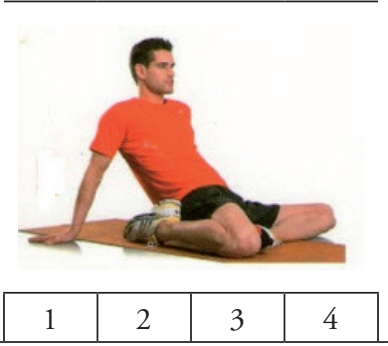

$(31)$

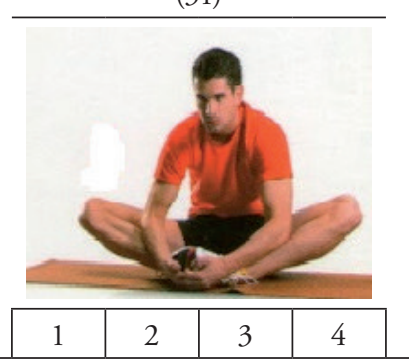

(32)

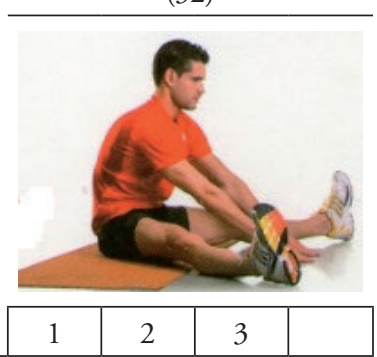

